\title{
SUMMATION OF CONTRACTION IN SINGLE CRAYFISH MUSCLE FIBRES
}

\author{
Haruo Sugi AND Kenji KosAKA* \\ Department of Physiology, Faculty of Medicine, University of Tokyo
}

It is well known that a vertebrate skeletal muscle may vary its tension development in two different ways: multifibre summation and wave summation (cf., Fulton, 1926). Concerning the multifibre summation it has been demonstrated by many authors that the individual mechanical tensions of the component fibres of a muscle sum additively. On the other hand, the mechanism of the wave summation, i. e., the summation due to a mechanical fusion of successive contraction waves within the individual fibres, is still a matter for speculation. Some investigators (e. g., HARTreE and Hill, 1921) tried to construct the curve of the second contraction by algebraically subtracting the single contraction curve from the fused one, on the assumption that the fusion is algebraical in character. On the contrary, Fulton (1925) and Hiramoto (1951) are of the opinion that the second contraction starts de novo from a new base-line at the level of which the first contraction is at the time.

It has long been recognized that the all-or-none nature of the contraction wave of a vertebrate muscle fibre is imposed by the all-or-none conducting action potential (cf., HUXLEY and TAYLOR, 1958). Graded twitch-like contractions which are not associated with an absolute refractory period have been recorded in fibres in which the action potential mechanisms had been lost (Brown and Sichel, 1936; Sichel and Prosser, 1940) or eliminated by immersion in a Na-free medium (HuXley and TAYloR, 1958; WATANABE, 1958).

The experiments to be described in this paper were made to study the mechanism of the summation of contraction within the individual fibres without involving the conducting action potential, using single crayfish muscle fibres which normally show graded and non-propagated contraction (e. g., NAGAI, 1953). The fibre was stimulated by transversely applied current pulses and the resulting mechanical responses were examined. It will be shown that the contraction elicited by a brief pulse is confined to the cathodal side, while the contraction may spread over the whole fibre with a prolonged pulse or repetitive brief ones. These results indicate that the increase in the

Received for publication June 26, 1964

* 杉 睛夫, 小坂健二 
number of activated contractile filaments may be involved in the process of summation of contraction in a crayfish muscle fibre.

\section{METHODS}

Single muscle fibres was isolated from the claw adductor of the crayfish (Cambarus clarkii), with a piece of tendon attached to one end and a piece of shell left at the other. The cross-section of the fibres showed a roughly elliptic shape; the major diameters ranged from 300 to $800 \mu$. The single fibre preparation obtained free of injury was placed in a rectangular trough of Acrylite $(2.4 \times 1.5 \times 1.0 \mathrm{~cm}$ deep $)$ filled with VAN HARREVELD's solution ( $\mathrm{NaCl} 230 \mathrm{mM}$, $\mathrm{KCl} 6 \mathrm{mM}, \mathrm{CaCl}_{2} 15 \mathrm{mM}, \mathrm{MgCl}_{2} 3 \mathrm{mM}$, $\mathrm{pH}$ adjusted to $7.2-7.4$ by $\mathrm{NaHCO}_{3}$ or TRIS-HCl buffer). A diagram of the experimental arrangement is shown in Fig. 1. The tendon end of the fibre was hooked to

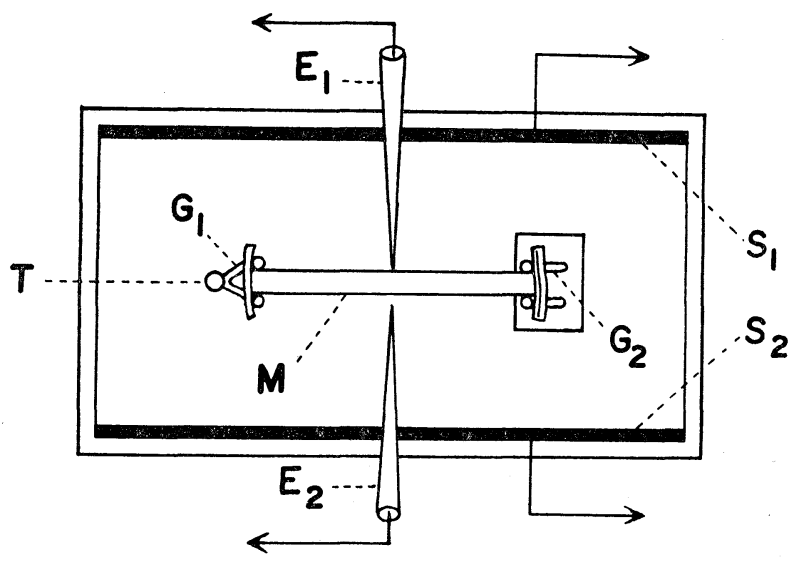

FIG. 1. Diagram of experimental arrangement. $\mathrm{E}_{1}, \mathrm{E}_{2}$ : microelectrodes connected to a pair of differential cathode followers. $G_{1}, G_{2}$ : glass hooks supporting the single fibre preparation (M). $\mathrm{S}_{1}, \mathrm{~S}_{2}: \mathrm{Ag}-\mathrm{AgCl}$ plate electrode sconnected to an electronic stimulator. T: Mechano-electric transducer (RCA 5734).

the tip of a glass capillary lever (about $3 \mathrm{~cm}$ long) attached to the anodal pin of a mechano-electric transducer (RCA 5734), while the shell side was supported with a glass hook fixed to the bottom of the trough. By means of a micromanipulator which held the transducer, the preparation was stretched horizontally $2-3 \mathrm{~mm}$ above the bottom of the trough until adequate isometric responses were obtained. The length of the fibre mounted in this way was $4-8 \mathrm{~mm}$ under the initial tension of 50 $100 \mathrm{mg}$.

The stimulating electrodes consisted of $\mathrm{Ag}-\mathrm{AgCl}$ plates covering two opposite internal walls of the' trough, and were placed parallel to the length of the fibre. Thus a rectangular current pulse from an electronic stimulator produced a transverse d. c. field up to $3.5 \mathrm{~V} / \mathrm{cm}$. The electrodes and the trough were sufficiently large compared with the fibre size for the electric field set up to be reasonably uniform and parallel. Two stimulators were used to supply two successive pulses; the intensity and the duration of each pulse could be varied independently. In some experiments, 
two successive pulses of opposite sign were produced by means of a relay driven by another stimulator. A $200 \Omega$ resistor was included in series with the electrodes to keep the stimulating current constant. Current intensity was measured by recording the potential difference across a $2 \Omega$ resistor between the bath and the ground. The bathing solution in the trough was sometimes exchanged with the aid of a water-vacuum suction tube.

The isometric tension and the stimulating current pulse were simultaneously displayed on a dual beam oscilloscope after amplification with two sets of DC amplifiers and recorded photographically. For calibration, known weights were applied to the glass lever attached to the transducer and it was ascertained that the deflection of the beam was linearly related to the applied weight in the range of measurements made in this study.

In some cases, the change in membrane potential during the application of the current pulse was examined differentially with a pair of glass capillary microelectrodes filled with $3 \mathrm{M} \mathrm{KCl}$ (tip diameter less than $0.5 \mu$ ), a pair of differential cathode followers connected to a balanced DC or RC (time constant $1.4 \mathrm{sec}$ ) amplifier and a oscilloscope. The microelectrodes were operated by two independent micromanipulators under a binocular microscope (magnification $\times 24$ ).

All the experiments were carried out at room temperature $\left(16-24^{\circ} \mathrm{C}\right)$.

\section{RESULTS}

1. Properties of graded tension responses. As shown in FIG. 2A, B, the tension response elicited by a transverse current pulse increased with the increase in the intensity of current pulses at constant duration or with the increase in the duration of current pulses at constant intensity. FIG. 2C, D are the records showing the early part of tension responses on a faster time base. The latent period of the tension response, i. e., the time between the beginning of stimulating current and the beginning of mechanical response, was constant (4-6 msec) irrespective of both the intensity (FIG. 2C) and the duration (FIG. 2D) of the current pulse except for the pulses of near the threshold intensity with which the latent period increased with decreasing current intensities. The latent period of tension response also remained constant over a wide range of initial tension applied to the fibre, from nearly zero to more than $500 \mathrm{mg}$.

Whether nervous elements in the muscle fibre is involved in the contraction is debatable. To make this point clear, some preliminary experiments were conducted in which the fibres were soaked in VAN HARREVELD's solution containing the drugs blocking the neuromuscular transmission in crustacea. The drugs tested were tetrodotoxin which inhibits contraction evoked by stimulation of the excitatory motor nerve (OGURA and MORI, 1963), and picrotoxin and guanidine which specifically inactivate the inhibitory synapse without changing the membrane resistance (GRUNDFEST, REUBEN and RickLES, 1959). Care was taken to avoid the deterioration of picrotoxin, because dissolved picrotoxin is labile in VAN HARREVELD's solution (ROBBINS and VAN 


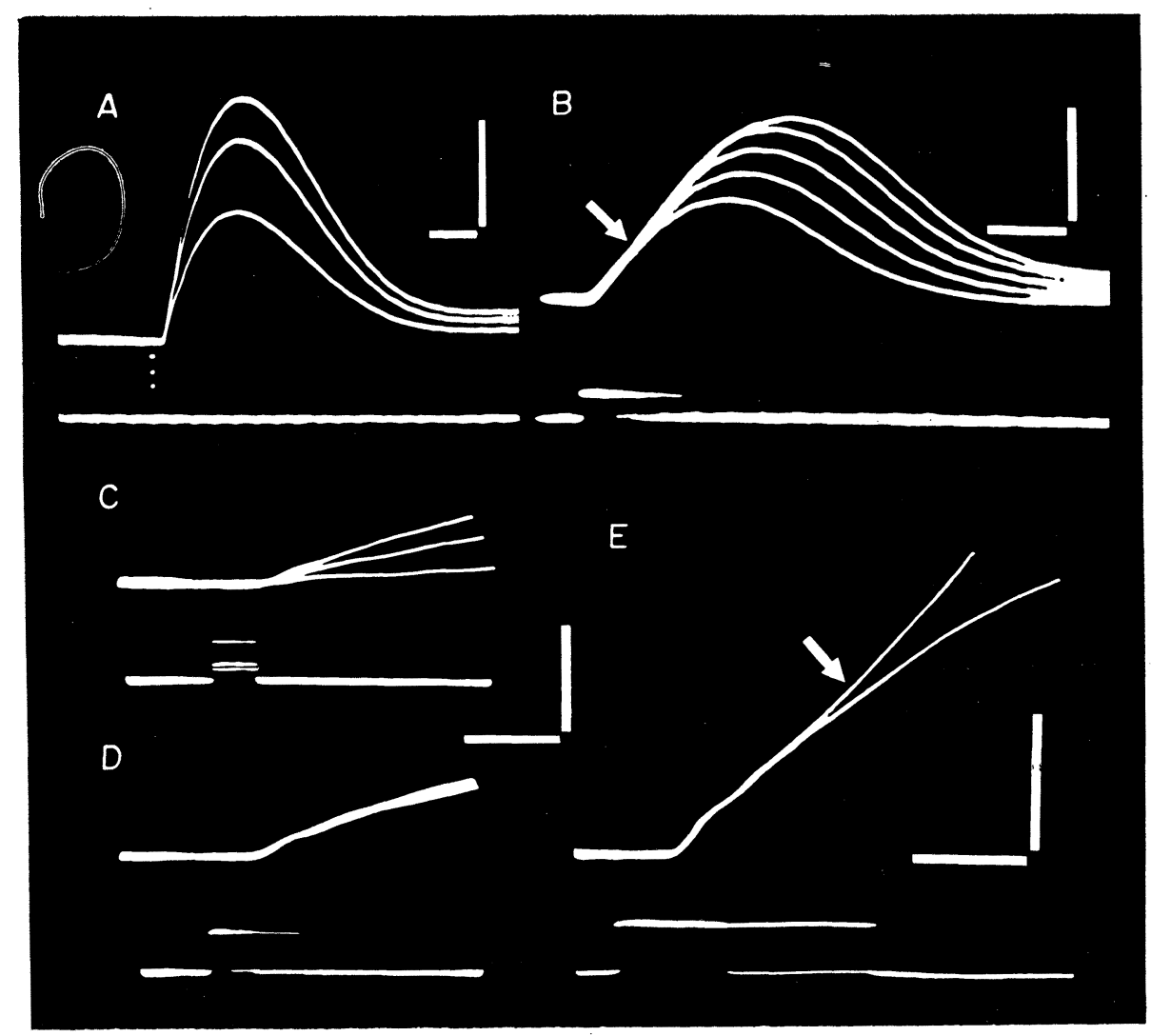

FIG. 2. Superimposed records of tension responses (upper traces) elicited by current pulses of varying intensities and durations (lower traces). The upward deflection of tension trace indicates an increase in tension in this and subsequent figures. A : Current pulses are of constant duration $(2 \mathrm{msec})$ and three different intensities $(1.0,1.5$ and $2.0 \mathrm{~V} / \mathrm{cm})$. B : Current pulses are of constant intensity $(2.5 \mathrm{~V} / \mathrm{cm})$ and four different durations $(40,50,60$ and $70 \mathrm{msec}) . \mathrm{C}, \mathrm{D}$ and $\mathrm{E}$ : Early part of tension responses on a faster time base showing the constancy of the latent period. Tension calibration: $200 \mathrm{mg}$ for A, $1 \mathrm{~g}$ for B, $300 \mathrm{mg}$ for C, D and $500 \mathrm{mg}$ for E. Time: $50 \mathrm{msec}$ for $\mathrm{A}, \mathrm{B}$ and $10 \mathrm{msec}$ for C, D, E. For further explanations see text.

DER KLOOT, 1958). Crystalline picrotoxin was dissolved in perfusion fluid about $10 \mathrm{~min}$ before each experiment. No significant change in shape, magnitude and latency of tension response was observed within 15-30 min after the application of tetrodotoxin $\left(10^{-6}-10^{-9} \mathrm{~g} / \mathrm{ml}\right)$, picrotoxin $\left(10^{-5}-10^{-8} \mathrm{~g} / \mathrm{ml}\right)$ and guanidine $\left(10^{-2}-10^{-3} \mathrm{~g} / \mathrm{ml}\right)$, It may therefore be concluded that neither excitatory nor inhibitory nerves are involved in the tension response elicited by the transverse current pulse. As a matter of fact, NAGAI (1953) found no local difference in excitability along the surface of crayfish claw adductor 
muscle fibres. Furthermore, VAN HARREveld (1939) pointed out that the feltwork-like nerve branches on the fibre surface are easily destroyed by dissection procedures.

FIG. 3 shows the relation between the peak height of mechanical response and the intensity of the current pulse at constant duration. It can be seen that the peak tension increases steeply for small increase in the current intensity above a critical value and finally reaches a plateau. The critical

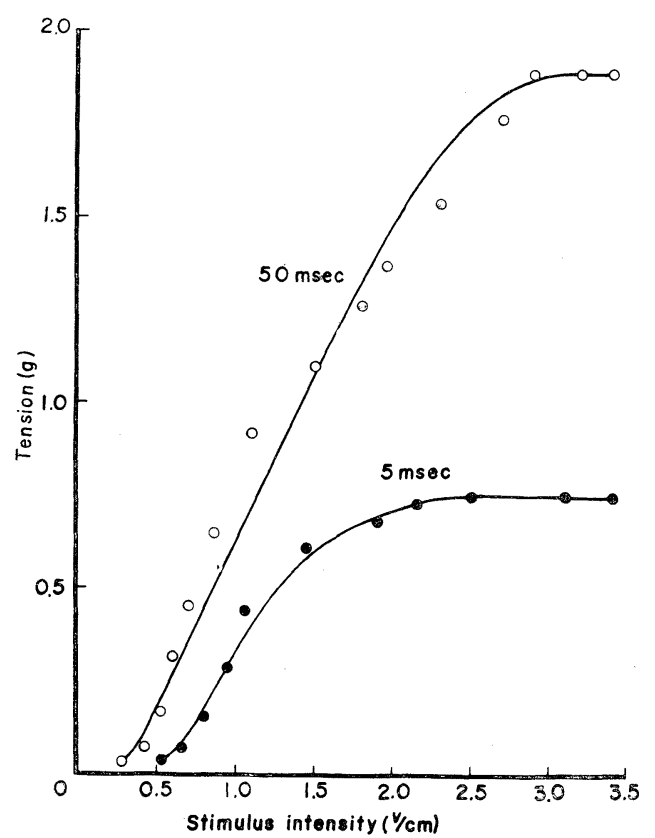

FIG. 3. Relation between peak tension and intensity of current at constant duration. Curves were obtained from one and the same fibre.

current intensity for development of just measurable tension varied with the current duration; the longer the current duration the smaller the critical current intensity. FIG. 4 shows the relation between the peak height of mechanical response and the duration of the current pulse at constant intensity. It will be seen that the peak tension also increases with increasing current durations; the stronger the current intensity the larger the rate of the increase in tension for a given increase in current duration. In fresh fibres, the peak tension reached a plateau with the application $3 \mathrm{~V} / \mathrm{cm}$ current for $0.25-1 \mathrm{sec}$.

An interesting feature was found concerning the rising phase of tension response. Records of tension developments produced by $3 \mathrm{~V} / \mathrm{cm}$ current pulses of two different durations are shown in FIG. 2E. With a $10 \mathrm{msec}$ pulse the tension rises abruptly from the base-line and no definite point of 


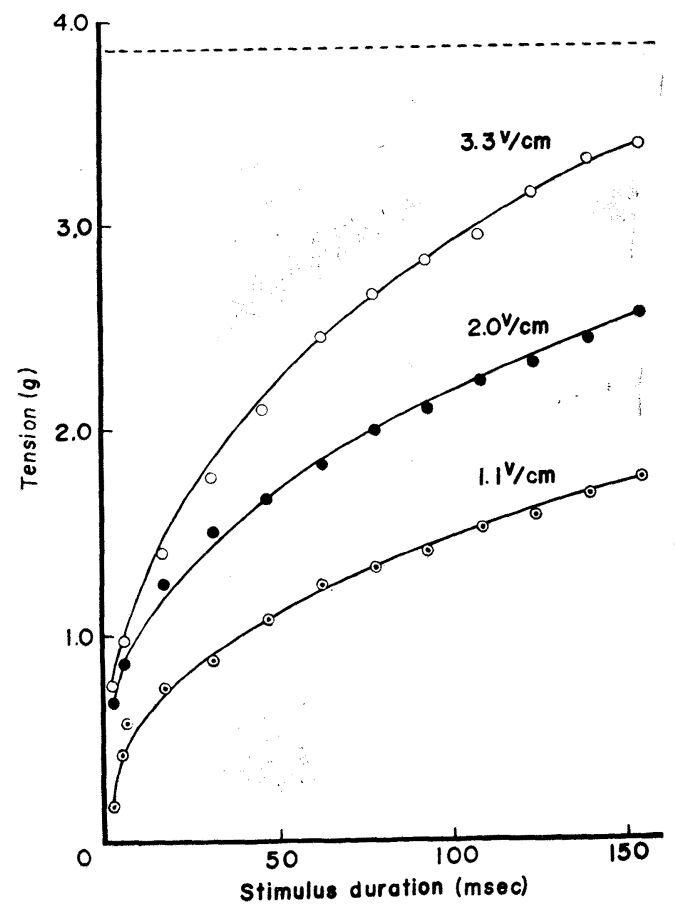

FIG. 4. Relation between peak tension and duration of current pulse at constant intensity. Curves were obtained from the same fibre. Broken line indicates maximum plateau tension attained by a prolonged $3.3 \mathrm{~V} / \mathrm{cm}$ current pulse.

inflection can be detectable in the subsequent rising phase of the tension response (lower tension trace). A similar time course of tension rise was observed in tension responses elicited by pulses of shorter durations (e.g., see FIG. 2A). Meanwhile, with a $20 \mathrm{msec}$ pulse it will be seen that there appears a point of inflection (indicated by the arrow) in the rising phase of the resulting tension response (upper tension trace). The point of inflection was also observable in tension responses elicited by pulses of longer than 20 msec (e.g., see early part of records in FIG. 2B indicated by the arrow). This result seems to suggest that there might be some change in the underlying processes leading to tension development if the stimulating current is maintained for more than $10-20$ msec.

2. Contraction observed in vertically suspended fibres. Under the experimental condition above-mentioned, it was not possible to know what part of a muscle fibre actually contracted. To answer this question, the following experiments were performed. The fibre was suspended vertically in a trough $(1.5 \times 0.8 \times$ $2.0 \mathrm{~cm}$ deep) filled with VAN HARREVELD's solution with a glass hook, a rela- 
tively large piece of shell attached to one end serving as a weight (FIG. 5A). The trough was mounted on the vertical stage of a horizontally fixed microscope for microscopic observation of the suspended fibre (magnification $\times 20$ ). Then the fibre was stimulated by transverse current pulses through a pair of $\mathrm{Ag}-\mathrm{AgCl}$ plate electrodes covering two opposite internal walls of the trough.

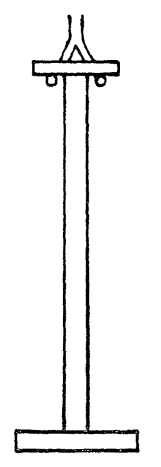

A

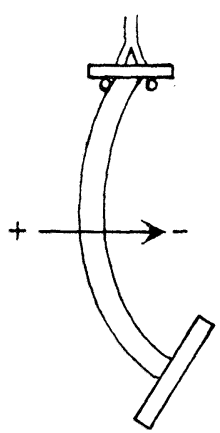

B

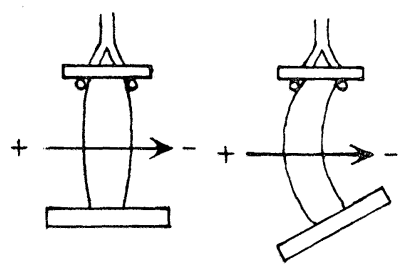

C
D

FIG. 5. Diagrams showing the behaviour of a suspended fibre in response to transverse current pulses. Arrows indicate current direction. A : Fibre extended. B: Bending in response to a brief pulse. C: Uniform contraction of the whole fibre by a prolonged current pulse. D: Contraction of a deteriorated fibre by a prolonged current pulse.

When a brief $(1-5 \mathrm{msec}$ ) pulse of sufficient intensity (above $2 \mathrm{~V} / \mathrm{cm}$ ) was applied, the fibre bent quickly into the form of an arc so that the cathodal side lay inside the arc (FIG. 5B). With pulses of weaker intensity, the bending of the fibre was slight and a crumpling of the fibre surface at the anodal side was observed. These results indicate that, with brief pulses, only the cathodal side of the fibre can be made to contract.

On the other hand, when the current was maintained for more than several tens of milliseconds, the bending of the fibre decreased gradually with the duration of current and finally the whole fibre contracted uniformly (FIG. 5C). The time of application of $3 \mathrm{~V} / \mathrm{cm}$ current necessary to bring the suspended fibre contract uniformly was roughly equal to that necessary to produce the maximum plateau tension in the isometric condition. After cessation of the current the fibre slowly relaxed to restore its initial extended state, though the restoration was in most cases incomplete, and such contraction of the whole fibre was reproducible at least two to several times. The fibres subjected more than several times to prolonged currents could no more contract uniformly; the cathodal side contracted more strongly than the anodal one (FIG. 5D). 
3. Summation of contraction by two successive pulses of opposite sign. Observations made on suspended fibres indicated that the contraction elicited by a brief pulse is confined to the cathodal side, while a prolonged current pulse may bring about the contraction of the whole fibre. To ascertain whether such is also the case under the isometric condition, the fibre was stimulated by two successive pulses of opposite sign so as to depolarize both sides of the fibre membrane by turns and the resulting summation of tension response was examined.

FIG. 6A is an example of superimposed records showing the summation of tension response by two successive brief pulses given at various intervals. It will be seen that the shorter the interval between stimuli the greater the height of the summated response. As shown in FIG. 7, the curve of the second response constructed by algebraically subtracting the single contraction curve from the summated one was constant both in shape and in mag-

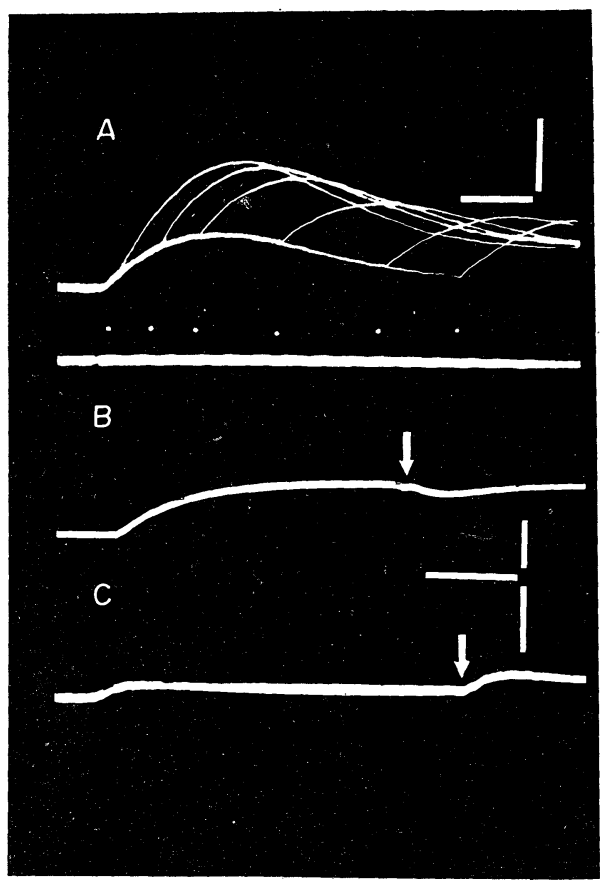

FIG. 6. Records of tension reponses produced by two successive brief or prolonged current pulses of opposite sign. A : Superimposed records of summation of tension response (upper traces) by two brief pulses (lower traces, $2 \mathrm{msec}, 3 \mathrm{~V} / \mathrm{cm}) . \quad \mathrm{B}$ and $\mathrm{C}$ : Tension responses in response to reversal of current direction. Currents $(3 \mathrm{~V} / \mathrm{cm})$ are maintained as long as tension response continued in these records. Arrows indicate moments of reversal of current direction. Record $B$ was obtained from a fresh fibre, while record $\mathrm{C}$ from a deteriorated one. Tension calibration: $500 \mathrm{mg}$ for $\mathrm{A}, 3 \mathrm{~g}$ for $\mathrm{B}$ and $1 \mathrm{~g}$ for $\mathrm{D}$. Time: $50 \mathrm{msec}$ for $\mathrm{A}$ and $0.5 \mathrm{sec}$ for $\mathrm{B}, \mathrm{C}$. 


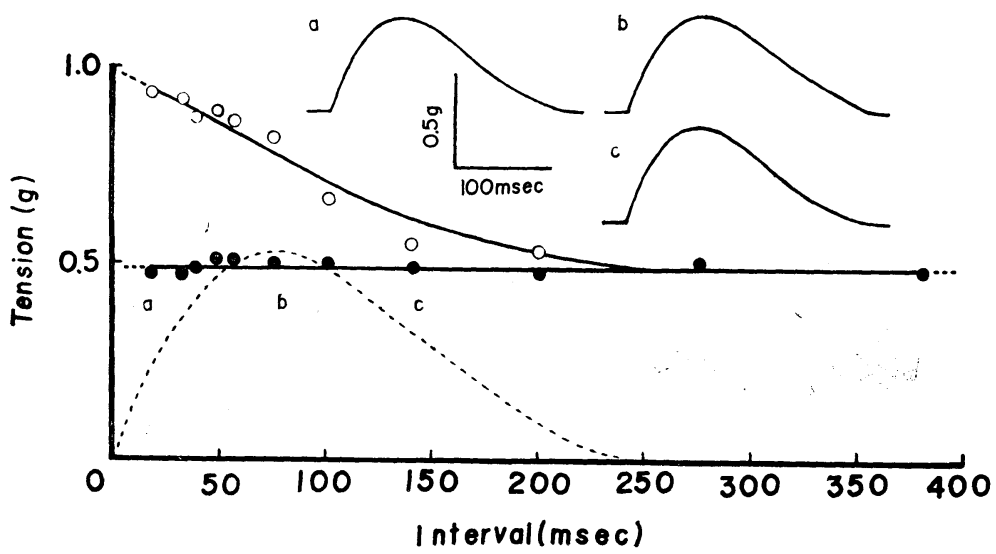

FIg. 7. Effect of change of interval between two brief stimulating pulses of opposite $\operatorname{sign}(2 \mathrm{msec}, 3 \mathrm{~V} / \mathrm{cm})$ on peak height of the summated response $(O)$ and that of the second one determined by algebraical subtraction of the single contraction curve from the summated one (O). Interval between stimuli represents the time between beginnings of two pulses. Broken line indicates the height of the first response at the moment when the second one begins. Three curves of the second responses constructed by the above-mentioned method are also shown in the upper part. Letters $\mathrm{a}, \mathrm{b}$ and $\mathrm{c}$ indicate points on the graph determined from the corresponding curves shown.

nitude irrespective of the interval between stimuli. Similar results as shown in Figs. 6A and 7 were obtained using two brief pulses of different duration and/or intensity to produce the summation of a small tension response and a larger one. Unfortunately it was not possible to apply the second pulse within $10 \mathrm{msec}$ after the cessation of the first one without some distortion, when an electronic relay was used for changing the current direction. This difficulty was overcome by applying the current pulse through two isolaters, though it was necessary to use much smaller stimulating electrodes $(0.5 \times 1.0$ $\mathrm{cm}$ ) for obtaining sufficient field strengths to induce tension responses. It was ascertained that the curve of the second response constructed by algebraical subtraction was also constant at shorter intervals. From these results it may be clear that the two tension responses elicited by two successive brief pulses of opposite sign sum additively. Such an algebraical character of summation may be easily explained by assuming that (1) the contraction elicited by a brief current pulse is confined to one side where the membrane is depolarized (cathodal membrane), and (2) the contraction, once elicited, is not affected by a subsequent membrane hyperpolarization at the same side.

On the other hand, it was found that the height of summated response by two pulses of longer durations never exceeded the level of the plateau tension attained by a prolonged current pulse of sufficient intensity (see FIG. 
4). Consequently, when the direction of a long maintained current was reversed after the plateau tension had been attained, no additional development of tension above the level of the plateau was observed; instead, the tension showed transient decrease and then redeveloped to the initial level as long as the current was maintained (FIG. 6B). As prolonged currents produced injurious effects on the fibre (STEN-KNUDSEN, 1954), such a maximum plateau level was reproducible at most several times, and subsequently the level of the plateau tension decreased each time the prolonged current pulse was applied. In such deteriorated fibres, an additional development of tension became observable at the reversal of current direction or at the break of the current. If the plateau level was reduced considerably, an additional tension as large as the plateau level was produced at the reversal of current direction (FIG. 6C). These results, together with the observations on the contraction in suspended fibres, may be taken to indicate that not only the cathodal side but also the anodal one of a normal fibre can be made to contract maximally with a prolonged transverse current pulse of sufficient intensity, while only the cathodal side contracts maximally in a deteriorated fibre.

4. Summation of contraction by two successive pulses of same sign. FIG. 8A is a typical example of the summation of tension response by two successive brief pulses of same sign. Contrary to the summation by two pulses of

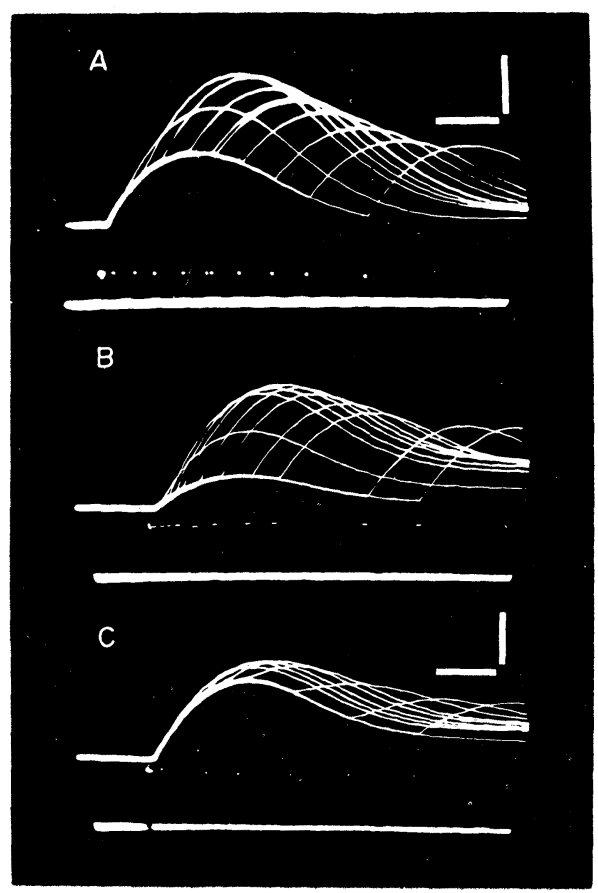

FIG. 8. Superimposed records showing summation of tension response (upper traces) by two successive pulses of same sign (lower traces). A: Summation by two brief pulses $(2 \mathrm{msec}, 3 \mathrm{~V} / \mathrm{cm})$. $\mathrm{B}$ and $\mathrm{C}$ : Summation by two pulses of unequal duration ( 1 and $6 \mathrm{msec}, 3 \mathrm{~V} / \mathrm{cm}$ ) obtained from one and the same fibre. In B shorter pulses were given before longer ones, while the sequence was reversed in $\mathrm{C}$. 
opposite sign (FIG. 6A), it will be seen that the height of the summated response is maximum when the second response starts from a definite point on the rising phase of the first one. As will be described later, this result is not associated with the summation of membrane depolarization. The latent period of the second response examined on a faster time base was also equal to that of the first one and constant irrespective of the interval between stimuli, except for extremely short intervals at which the beginning of the second response could hardly be detectable. In FIG. 9 the height of

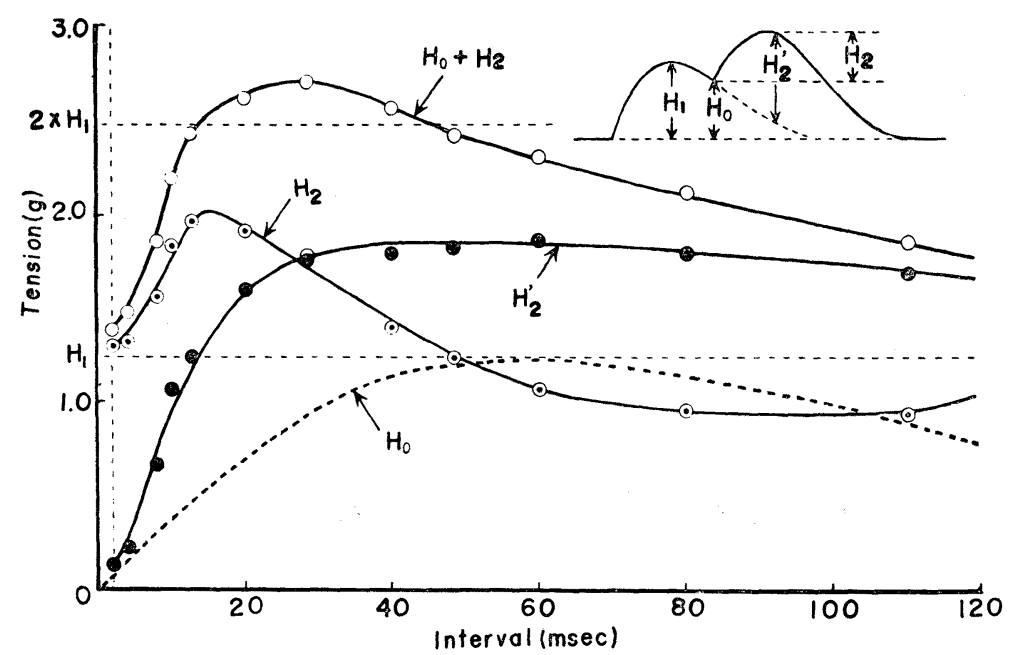

FIG. 9. Effect of change of interval between two brief stimulating pulses of same $\operatorname{sign}(2 \mathrm{msec}, 3 \mathrm{~V} / \mathrm{cm})$ on peak height of the summated response $\left(\mathrm{O}, \mathrm{H}_{0}+\mathrm{H}_{2}\right.$ in the accompanying diagram, and that of the second one determined by algebraical subtraction $\left(\mathrm{H}_{2}^{\prime}\right)$ or measured from a new base-line, i.e., from the level of $\mathrm{H}_{0}\left(\mathrm{O}_{2}, \mathrm{H}_{2}\right)$. Broken line indicates the height of the first response at the moment when the second one begins $\left(\mathrm{H}_{0}\right)$. Since the beginning of the second response was hardly detectable at intervals shorter than $4 \mathrm{msec}$, these values were measured on the assumption that the latent period of the second response remained unchanged up to the shortest interval. Note that the maximum height of the summated response is more than twice the height of the single response $\left(\mathrm{H}_{1}\right)$.

the summated response $\left(\mathrm{H}_{0}+\mathrm{H}_{2}\right)$, and that of the second response determined by algebraical subtraction in the same way as HARTREE and HILL (1921) $\left(\mathrm{H}_{2}^{\prime}\right)$ or measured from the level $\left(\mathrm{H}_{0}\right)$ at which the second response starts by the method of FULTON (1925) and HiRAmoto (1951) $\left(\mathrm{H}_{2}\right)$ are plotted against the interval between stimuli. Similar results were obtained on the summation of tension response by two pulses of various durations $(1-15 \mathrm{msec})$ and intensities $(0.8-3.5 \mathrm{~V} / \mathrm{cm})$. Roughly speaking, the mode of summation of contraction in single crayfish muscle fibres shown in FIGS. 8A and 9 is analogous to 
that of summation of all-or-none twitch in vertebrate muscles (e.g., Fulton, 1925 ; CoOper and Eccles, 1930) or single fibres (Hiramoto, 1951), except that these authors could not examine the process of summation precisely up to the shortest interval between stimuli because of the absolute refractory period.

FIG. 8B, C are the records obtained from one and the same fibre which was stimulated by two successive pulses of different duration. In FIG. 8B, the shorter pulse preceded the longer one so as to cause the larger response on the smaller one, whereas the above sequence was reversed in FIG. 8C. It will be seen that, in both cases, the height of the summated response is maximum when the second response begins at a definite point on the rising phase of the first one as in Fig. 8A. It was always found that the maximum height of the summated response was larger if the shorter pulse preceded the longer one than if the above sequence was reversed.

5. Summation by repetitive brief pulses. The maximum plateau tension produced by a prolonged current pulse of sufficient intensity (see FIG. 4) was also attained by repetitive brief (1-5 msec) pulses of sufficient intensity given at more than $20-30 / \mathrm{sec}$. When the current direction of pulses was reversed after the fibre had been fully tetanized, no additional tension above the level of the tetanus tension was observed; records analogous to that in FIG. 6B was obtained. This indicates that the maximum plateau tension attained by a prolonged current pulse is identical with the tetanus tension resulting from the fusion of small tension response elicited by each brief pulse.

6. Change in membrane potential during the application of stimulating current pulse. As it is generally believed that the first step leading to contraction in striated muscle is a reduction of membrane potential (e. g., Kuffler, 1946; HuXley and TAYlor, 1958; Watanabe, 1958; Orkand, 1962), it seemed desirable to examine the change in membrane potential at the cathodal side of the cell membrane during the application of transverse current pulse. This was carried out by measuring the potential difference across the cell membrane differentially with a pair of glass capillary microelectrodes in the following way:

One microelectrode was made just in contact with the fibre surface facing to the cathode of the stimulating electrodes, while the other was placed in the outside medium so that no potential difference could be detected between the two microelectrodes before and during the application of stimulating pulse except for capacitive pickups at the onset and removal of the current. Then the microelectrode in contact with the fibre surface was inserted into the fibre with minute additional movement, and the potential difference across the cathodal side of the cell membrane produced by the stimulating current 


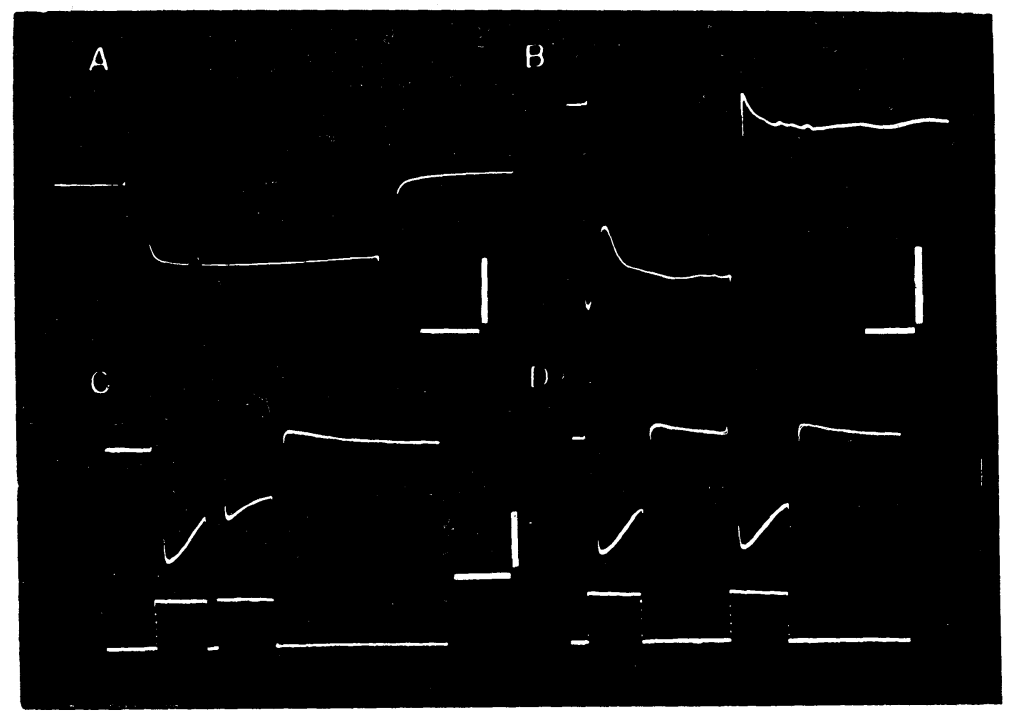

FIG. 10. Membrane potential changes at the cathodal side of the fibre recorded differentially during application of stimulating current pulses. In each record, inside positive direction of potential downwards. A : a pleteau of depolarization produced by a current pulse $(1.5 \mathrm{~V} / \mathrm{cm}$, $9 \mathrm{msec})$. B: Active membrane response at the early part of potential change produced by a stronger current pulse $(3.5 \mathrm{~V} / \mathrm{cm}, 30 \mathrm{msec}) . \quad \mathrm{C}$ and D: Active membrane responses (upper traces) produced by two successive brief current pulses (lower traces, $5 \mathrm{msec}, 3 \mathrm{~V} / \mathrm{cm}$ ) on a faster time base. Note that the amplitude of active membrane response decreases when the second pulse is given within a few msec after removel of the first. Potential calibration $30 \mathrm{mV}$ for $A$ and $50 \mathrm{mV}$ for B, C, D. Time: $2 \mathrm{msec}$ for $\mathrm{A}, 10 \mathrm{msec}$ for $\mathrm{B}$ and $5 \mathrm{msec}$ for $\mathrm{C}, \mathrm{D}$.

pulse was recorded. In most cases, the change in membrane potential across the cathodal membrane was a plateau of depolarization which was sustained as long as the current pulse continued (FIG. 10A). The amount of depolarization increased in parallel with the increase in the current intensity, and, unlike the height of the resulting tension response, never reached an upper limit; it sometimes exceeded the amount of the resting membrane potential of $60-80 \mathrm{mV}$ with pulses of above $3 \mathrm{~V} / \mathrm{cm}$. Some fibres showed a spike-like transient potential change at the beginning of the plateau of depolarization (FIG. 10B). This may be attributed to the active membrane response initiated by an outward flow of the stimulating current at the cathodal membrane (c. f., ORKANd, 1962; Atwood, 1963; Hoyle and Smyth, 1963). The change in membrane potential was measured at several points along the cathodal side, and it was found that the amount of depolarization was fairly uniform along the length of fibre, indicating that the fibre could be stimulated fairly uniformly along its length. 
Depolarizations produced by successive current pulses did not summate even when the second pulse was given a few msec after the removal of the first one. Therefore, the possibility that the summation of depolarization is involved in the process of summation of contraction may be excluded. The height of the active membrane response initiated by the second pulse decreased at extremely short intervals (FIG. 10C, D).

Meanwhile, hyperpolarizations were recorded across the anodal side of the cell membrane during the application of current pulses. The amount of hyperpolarization was also fairly uniform along the anodal side of the cell membrane.

The opportunity was also taken to examine the relation between membrane potential and tension with the aid of intracellular stimulation and recording techniques. Like other crustacean muscle fibres (ORKAND, 1962; ATwOoD, 1963), the contractile tension responded in a graded manner to depolarizations produced by outward currents through an intracellular microelectrode, increasing steeply for small increase in depolarization above the mechanical threshold.

\section{DISCUSSION}

Graded contractions in single crayfish muscle fibres described in this paper resemble closely those in single frog muscle fibres in which the all-ornone conducting action potential is lost (BRown and SicheL, 1936), though a definite upper limit of tension response for a given stimulus duration as shown in FIG. 3 has not been observed in the latter. Sichel and Prosser (1941) studied the summation of the graded contraction in single frog fibres and reported, contrary to the present results on the summation by two pulses of same sign, that the height of the summated response was maximum when two stimuli (transversely applied condenser discharges) were given synchronously. This may be explained as being due to the summation of two submaximal stimuli given synchronously or at short intervals to constitute a stronger stimulus. Thus the resulting response may become much larger than that by single submaximal one, since the height of tension response increases steeply for small increase in the stimulus intensity (c. f., Brown and SicheL, 1936).

In the present study, it was possible to examine the summation of contraction by two transverse current pulses of same sign up to the shortest interval without involving the summation of the resulting membrane depolarization at the cathodal side. Although the validity of comparing the summation of the graded contraction with that of the all-or-none contraction is not clear at present, the result that the height of the summated response was maximum when the second response began at a definite point on the rising 
phase of the first one seems in agreement with the result of CoOPER and ECCLES (1930) on the cat muscle stimulated indirectly, and different from that of HARTREE and Hill (1921) on the frog muscle stimulated directly in which the height of the summated response was maximum when the second response started from the peak of the first one. HILl (1949) claimed that the result of COOPER and ECCLES might be due to the summation at the neuromuscular junction which mask the purely muscular effect. However, as described previously, the possibility that the nervous elements are involved in the summation of contraction may be denied in this work.

The behaviour of suspended fibres in response to a brief current pulse and the algebraical nature of summation of tension response by two brief pulses of opposite sign have clearly demonstrated that the contraction elicited by a brief current pulse is confined to the cathodal side of the fibre. Since a definite upper limit of tension response has been obtained for each stimulus duration (FIG. 3), it follows that a brief pulse, however strong it may be, can only activate the myofilaments located near the fibre surface where the membrane is depolarized. On the other hand, when the fibre was subjected to a prolonged current pulse or a series of repetitive brief ones of sufficient intensities, the whole fibre contracted uniformly within about 1 sec. This may be taken to indicate that a depolarization of the whole fibre surface is not necessary for the contraction of the whole fibre; the contraction can spread to the anodal side where the membrane in hyperpolarized.

Then the question arises how the contraction initiated first at the cathodal side may spread to the anodal side during the application of transverse stimulating currents. One possibility may be that the transversely arranged components of sarcoplasmic reticulum is concerned in such a transverse spread of contraction (c. f., HUXLEY and TAYLOR, 1958); the transverse tubular system might serve the spread of contraction not only from the surface to the center but also from the center to the surface of the fibre. Recently, GIRARDIER, REUBEN, BRANDT and GRUNDFEST (1963) have shown that the membrane of the transverse tubular system in crayfish muscle fibres is anion-permselective and put forward an interesting hypothesis that a local accumulation of cations near the membrane of this tubular system triggers the contraction. However, the mechanism of transverse spread of contraction cannot be discussed further until the properties of transverse spread and also the spatial arrangements of the tubular system are known in more detail.

Apart from the above problem, the present results have indicated that the summation of contraction by two pulses of same sign is not a simple temporal summation but composed of both temporal and spatial ones; a temporal summation in the myofilaments located close to the fibre surface where the membrane is depolarized, and a spatial summation, i.e., the increase in the number of activated myofilaments running parallel with each 
other within a crayfish muscle fibre. Thus, at least, as far as the crayfish muscle fibre is concerned, the mechanism of summation of contraction may not be solved unless the mechanism of transverse spread of contraction is clarified. Furthermore, whether such is also the case in the summation of the all-or-none twitch of vertebrate muscle fibres seems to deserve an investigation.

The present results strongly suggest that the gradation of contraction depending on the frequency of motor nerve impulses in crustacean muscle fibres is achieved, to a great extent, by changing the number of activated myofilaments within a muscle fibre. It is well established that, in crustacean muscle fibres, motor nerve terminals are distributed at many points along the fibre surface (e.g., KATZ, 1949), and each nerve impulse causes in most cases only a small electrical response, i. e., junction potential confined to each nerve terminal; a large amount of depolarization around the whole fibre surface may be produced by the summation and facilitation of junction potentials (e. g., Hoyle and Wiersma, 1958). Thus, it may not be unreasonable to suppose that only the myofilaments located close to the fibre surface may be involved in a small mechanical response produced by a single nerve impulse or a series of nerve impulses given at low frequencies, while the myofilaments at the center of the fibre may be activated by the spread of contraction from the fibre surface to produce a much larger mechanical response if a large amount of depolarization is built up and maintained for a sufficiently long time by a series of nerve impulses given at high frequencies. In this connection, it is of interest that, in some crustacean abdominal muscles, the component fibres are twisted both individually and in bundles. These muscles show a rapid, twitch-like contraction and clearly serve for a rapid movement of the abdomen. If it is assumed that most of the "fast" motor nerve terminals are distributed along the inner side of a twisted fibre (c.f. WIERSMA and WRIGHT, 1947), the functional significance of this arrangement might be to develop a large force rapidly, since the myofilaments at the innervated side may be activated more readily than those at the non-innervated side according to the above hypothesis. This possibility has already been suggested by WIERSMA (1961).

\section{SUMMARY}

1. Single muscle fibres isolated from the claw adductor of the crayfish were stimulated directly by transversely applied rectangular current pulses and the resulting contractions were studied.

2. The height of tension response increased with the increase in the intensity of the current at constant duration or with the increase in the duration of the current at constant intensity, and reached a plateau in both cases. 
3. The behaviour of suspended fibres in response to a brief pulse and the algebraical summation of tension response by two brief pulses of opposite sign have shown that the contraction elicited by a brief pulse is confined to the cathodal side of the fibre.

4. On the other hand, the whole fibre could be made to contract uniformly by a prolonged current pulse or a series of repetitive brief ones of sufficient intensities. This may be taken to indicate that the membrane depolarization around the whole fibre surface may not be necessary to bring the whole fibre to contract uniformly.

5. Using two pulses of same sign, it was possible to examine the summation of contraction up to the shortest interval without involving the summation of depolarization.

6. From these results it is concluded that the increase in the number of activated myofilaments may be involved in the process of summation by two pulses of same sign. The possible mechanism of the gradation of contraction in crustacean muscles was also discussed in this connection.

We wish to thank Professor K. Uchizono for his constant advice and kind help in the preparation of the manuscript. Our thanks are also due to Professor H. Kinosita and Dr. Y. Hiramoto for their fruitful suggestions and to Professor T. WAKABayashi, Professor A. Takeuchi, Dr. M. Ito and Dr. K. Toyama for stimulating discussions.

\section{REFERENCES}

ATwood, H.L. (1963) Differences in muscle fibre properties as a factor in "fast" and "slow" contraction in Carcinus. Comp. Biochem. Physiol. 10:17-32.

Brown, D. E.S. ANd Sichel, F. J.M. (1936) The isometric contraction of isolated muscle fibres. J. Cell. Comp. Physiol. 8 : 315-328.

CoOper, S. AND Eccles, J.C. (1930) The isometric responses of mammalian muscles. J. Physiol. 69: 377-385.

Fulton, J.F. (1925) On the summation of contractions in skeletal muscle. Am. J. Physiol. 75 : 211-234.

Fulton, J.F. (1926) Muscular contraction and the reflex control of movement. Baltimore: Williams \& Wilkins.

Girardier, L., Reuben, J.P., Brandt, P. W. And Grundfest, H. (1963) Evidence for anion-permselective membrane in crayfish muscle fibres and its possible role in excitation-contraction coupling. J. Gen. Physiol. 47: 189-214.

Grundfest, H., Reuben, J.P. And Rickles, W. H. Jr. (1959) The electrophysiology of lobster neuromuscular synapses. J. Gen. Physiol. 42 : 1301-1323.

Hartree, W. And Hill, A. V. (1921) The nature of the isometric twitch. J. Physiol. $55: 389-411$.

Hill, A. V. (1949) The abrupt transition from rest to activity in muscle. Proc. Roy. Soc. B, 136: 399-420.

Hiramoto, Y. (1951) Propagation of contraction wave in single muscle fibres. II. Summation of contraction waves. Annot. Zool. Japon. 24 : 150-156.

Hoyle, G. And Smyth, T. Jr. (1963) Neuromuscular physiology of giant muscle fibres 
of a barnacle, Balanus nubilus Darwin. Comp. Biochem. Physiol. 10 : 291-314.

Hoyle, G. And Wiersma, C. A.G. (1958) Excitation at neuromuscular junctions in crustacea. J. Physiol. $143:$ 403-425.

Huxley, A. F. AND TAylor, R.E. (1958) Local activation of striated muscle fibres. J. Physiol. $144:$ 426-441.

KAtz, B. (1949) Neuromuscular transmission in invertebrates. Biol. Rev. 24: 1-20.

Kuffler, S. W. (1946) The relation of electric potential changes to contracture in skeletal muscle. J. Neurophysiol. 9: 367-377.

NAGAI, T. (1953) Physiological studies on crustacean muscle fibres I. Electrical stimulation and types of contraction. Annot. Zool. Japon. 26 : 57-63.

Ogura, Y. ANd Mori, Y. (1963) Effect of crystalline tetrodotoxin on the crayfish nerve-muscle preparation. Ann. Rept. Inst. Food. Microbiol. (Chiba Univ.) 16: 64-71.

ORKAND, R.K. (1962) The relation between membrane potential and contraction in single crayfish muscle fibres. J. Physiol. 161: 143-159.

Robbins, J. AND VAN DER Kloot, W.G. (1958) The effect of picrotoxin on peripheral inhibition in the crayfish. J. Physiol. $143: 541-552$.

Sichel, F. J. M. And Prosser, C. L. (1940) Summation and the absence of a refractory period in isolated skeletal muscle fibres. Am. J. Physiol. 128: 203-212.

Sten-Knudsen, O. (1954) The ineffectiveness of the "window field" in the initiation of muscle contraction. J. Physiol. 125: 396-404.

VAN HARREveld, A. (1939) The nerve supply of doubly and triply innervated cray. fish muscle related to their function. J. Comp. Neurol. $70: 267-284$.

WATANABE, A. (1958) Initiation of contraction by transverse and longitudinal current flow in single muscle fibres. Jap. J. Physiol. $8: 123-137$.

Wiersma, C. A. G. (1961) The neuromuscular system. In the physiology of crustacea, 2, Ed. Waterman, T.H. New York: Academic Press.

Wiersma, C. A. G. AND Wright, E.B. (1947) The nature of the action potentials of crustacean muscles. J. Exp. Biol. $23: 205-212$. 